\title{
FORMA CENTRAL DA MOLÉSTIA NERVOSA DE RECKLINGHAUSEN
}

\author{
L. C. Mattosinho FranÇA * \\ Gilberto Machado de Almeida *:
}

Von Recklinghausen, em 1882, descreveu a neurofibromatose como moléstia caracterizada por pigmentação anormal, desordens neoplásticas da pele e tumores do sistema nervoso periférico; alguns anos mais tarde, descreveu a moléstia fibrocística dos ossos. Estas duas entidades são designadas pelo nome dêste autor, reservando-se à primeira o título de moléstia nervosa e. à segunda, o de moléstia óssea. A neurofibromatose já havia sido referida anteriormente por Wishart em 1822 (cit. por Rasmussen ${ }^{1 i}$ ), por R. W. Smith em 1849 (cit por Lichtenstein i) e por vários outros, sem que, entretanto, fôsse reconhecida como entidade mórbida isolada. Esta moléstia, atingindo vários sistemas e de patogenia complexa, foi bastante estudada nos anos que se seguiram às publicações de Recklinghausen. Landowski (1894) descreveu, como sinais fundamentais, a existência de manchas hiperpigmentadas da pele, de tumores cutâneos e de tumores dos nervos. Mossé e Cavalié (cit. por Rasmussen ${ }^{1}$ ) designaram como forma central da neurofibromatose a ocorrência de tumores radiculares múltiplos, reservando a designação de forma periférica aos casos que apresentam apenas a triade de Landowski. Henschen (cit. por Rasmussen ${ }^{1 i}$ ), Cushing (cit. por Gardner ${ }^{4}$ e Penfield ${ }^{13}$ ), Gardner ${ }^{4,5}$ e Rasmussen ${ }^{17}$ estudaram os tumores bilaterais do nervo acústico, isolados ou associados a outros tumores intracranianos e à forma periférica da moléstia de Recklinghausen. Até 1941 haviam sido descritos cêrca de 50 casos da forma central, dos quais uma sexta parte era constituída exclusivamente por tumores bilaterais do acústico. Bielschowski (cit. por Penfield ${ }^{13}$ e Bassoe ${ }^{2}$ ), seguido por Penfield e Young ${ }^{13}$, demonstrou a existência de atipias celulares nos cérebros de portadores de neurofibromatose e relacionou esta moléstia à esclerose tuberosa. Van der Hoeve (cit. por van Bogaert ${ }^{22}$ ) estudou as alterações retinianas encontradas na neurofibromatose, referindo semelhanças entre as mesmas e as encontradas nos casos de moléstia de Bourneville ou de Von Hippel. Thannhauser 21, apoiado em estudos de Masson " e usando a divisão da moléstia fibrocística dos ossos em formas generalizada e disseminada. associou a forma disseminada à neurofibromatose em sua manifestação óssea.

Trabalho da Clínica Neurológica (Prof. Adherbal Tolosa) e do Departamento de Patologia Geral e Anatomia Patológica (Prof. L. da Cunha Mota) da Faculdade de Medicina da Universidade de São Paulo. Apresentado no Departamento de NeuroPsiquiatria da Associacão Paulista de Medicina em 5 de dezembro de 1957 . Assistente voluntário de Anatomia Patológica. * Médico residente de Clínica Neurológica. 
Atualmente, após descrição de várias lesões encontradas na moléstia de von Recklinghausen, são reconhecidas cinco síndromes: cutânea, nervosa (central e periférica), óssea, visceral e endócrina.

A sistematização das lesões encontradas na moléstia nervosa de Recklinghausen pode ser feita da seguinte forma:

1. Alterações tegumentares: a) manchas cutâneas hiperpigmentadas, de forma e tamanho variado, tendo como característico fundamental a inexistência de células névicas no derma; b) nevos vinhosos e angiomas cutâneos.

2. Alteraçōes do sistema nervoso periférico: a) neurofibromas - neurofibromas de fasciculos assimétricos segundo Masson ", correspondentes ao tipo B de Antoni -- que são tumores benignos constituídos por feixes de tecido colágeno atravessados por fibras nervosas isoladas; b) neurite intersticial hipertrófica - neurofibromas de fascículos simétricos segundo Masson ${ }^{9}$ - constituída por feixes de fibras colágenas e células alongadas, dispostas segundo o longo eixo de fibras nervosas; c) neurinomas - schwannogliomas segundo Masson ", fibroblastomas perineurais segundo Mallory e Penfield 11, 12, 1:3, correspondentes ao tipo A de Antoni - constituídos por células alongadas, dispostas em feixes, por vêzes em paliçada; êstes tumores são ricos em fibras colágenas e reticulinicas e desprovidos de fibras nervosas. Segundo Penfiel ${ }^{11}, 12,1: 3$ o neurofibroma é o processo característico da moléstia de Recklinghausen; entretanto, sôbre um neurofibroma, pode se instalar um neurinoma (schwannoglioma ou fibroblastoma perineural); isto explica a coexistência, em um mesmo tumor, de aspectos correspondentes aos dois tipos de Antoni; chamaremos, então, de neurofibromas aos tumores que caracterizam a moléstia.

3. Alterações do sistema nerroso central, meninges e raizes: a) neurofibromas radiculares múltiplos, com localizações preferenciais nas raizes medulares, nos nervos acústicos e, com menor freqüência, nos V, VII, IX, X e $\mathrm{XI}$ nervos cranianos; b) meningeomas múltiplos, mais freqüentes na duramater da calota craniana e na dura-mater espinal, sendo raramente originados nos plexos coróides; c) ninhos de células gliais atípicas, com localização preferencial no córtex cerebral; d) hiperplasia da glia marginal do cerebelo, com invasão do espaço subaracnóideo (pontes fibrocelulares, Ajuriaguerra e col. $\left.{ }^{1}\right)$; e) gliose difusa do sistema nervoso central (Scharenberg e Jones ${ }^{19}$ ); f) tumores de nutureza glial, especialmente ependimomas, astrocitomas e espongioblastomas; $g$ ) angiomas ou hiperplasia vascular focal, com aspecto angiomatoso e hialinização das paredes vasculares, localizados preferencial-

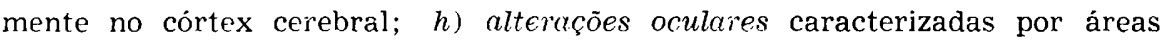
de inflamação no corpo ciliar, degeneração e transformação cística da retina, hiperplasia focal de elementos gliais e neuronais, bem como de vasos e tecido conjuntivo.

4. Alterações ósseas: cistos ósseos isolados ou múltiplos, não acompanhados de desmineralização esquelética, elevação do cálcio sangüíneo ou cal- 
cificações metastáticas; o conteúdo dos cistos é constituído por tecido conjuntivo disposto à maneira de feixes entrecruzados, com formação de turbilhões celulares, sempre contiguos ao periósteo.

5. Alterações viscerais: com ou sem a formação de tumores, podendo haver gigantismo de uma víscera.

6. Alterações endócrinas: a) hipertrofia ou esclerose da suprairenal; b) hipertrofia ou esclerose da hipófise; c) neurofibroma da suprarrenal; d) alterações causadas por pressão sôbre o $3^{\circ}$ ventriculo por neurofibroma central ou pela hipertensão intracraniana.

Em sua descrição original, Recklinghausen julgou serem os tumores cutâneos falsos neuromas, constituídos por hiperplasia do tecido conjuntivo do endo e perinervo, hiperplasia esta dependente de um provável fator infeccioso. As discussões sôbre a natureza dos tumores estão centradas na interpretação dos neurofibromas e neurinomas, sendo os pontos fundamentais de discordância referentes à natureza das células e fibras que os constituem.

Os autores da escola francesa admitem que as células constituintes dos tumores sejam células de Schwann. Além disso, Lhermite, Guccioni e Verocay julgam que o componente fibrilar seja constituido por fibras nervosas prcduzidas pelas próprias células tumorais. Dai o nome de neurinoma criado por Verocay, nome que, apesar de impróprio, continua a ser usado para designar um dos tipos de tumor proveniente das bainhas dos nervos. Oberling, Cornil e Roussy (cit. por Lichtenstein `) considerando as células de Schwann e as meninges como constituindo a glia periférica, classificam êstes tumores das bainhas dos nervos como gliomas periféricos.

Masson", aceitando a demonstração feita por Rhoads e Van Wagenen de que as fibras contidas nos tumores são de natureza conjuntiva e usando dados de cultivo de tecido, fornecidos por Murray e Stout, de que o sincício de Schwann produz colágeno assim como dá origem ao endo e perinervo, sustenta a idéia de que tais tumores se originem a partir da bainha de Schwann. Partindo de dados que demonstram que a bainha de Schwann e as meninges originam-se da crista neural, Masson descreve, como caracteristica dos neoplasmas derivados dêstes envoltórios do sistema nervoso, a formação de turbilhões celulares. Masson reune em uma única patogenia os schwannogliomas (neurinomas), os neurofibromas de fasciculos assimétricos (neurofibromas) e os neurofibromas de fascículos simétricos (neurite intersticial hipertrófica), uma vez que todos resultam do crescimento anômalo da bainha de Schwann. A origem dos neurofibromas (fasciculos simétricos e assimétricos) é disgenética. Nos schwannogliomas (neurinomas) o crescimento aparece como propriedade autônoma, blastomosa, sem relação com alterações primárias dos neuritos.

Mallory (cit. por Penfield 11,13), considerando que fibras colágenas e reticulínicas só podem ser produzidas por células conjuntivas, deu aos neurinomas a denominação de fibroblastomas perineurais e, aos meningeomas, a de 
fibroblastomas meníngeos. Como as fibras dêstes tumores sāo colágenas e reticulínicas, a origem fibroblástica dos mesmos se impōe. Penfield 11, 12, 13, considera os neurofibromas como característicos da moléstia de Recklinghausen, não sendo, no entanto, tumores verdadeiros, mas sim malformações; sôbre os neurofibromas se desenvolveriam, secundàriamente, os tumores (neurinomas ou fibroblastomas perineurais de acôrdo com a nomenclatura da escola americana). sendo explicada, assim, a existência dos dois processos na mesma tumoração. As duas escolas (francesa e americana) acreditam, portanto, que o neurofibroma tenha origem disgenética, ao passo que o neurinoma é considerado como verdadeira neoplasia.

Lichtenstein ' considera as lesões encontradas na neurofibromatose como devidas a uma perturbação do desenvolvimento, com capacidade de transformação neoplásica dos tecidos de suporte do sistema nervoso, tanto intrínsecos (prolongamentos de células ependimárias, astroglia, oligodendroglia, células de Schwann) como extrinsecos (meninges, endo e perinervo), admitindo. assim, uma interpretação eclética. Pagès e col. ${ }^{\text {" }}$ também admitem uma tecria dualista para explicar o caráter polimorfo das lesões.

Henneberg e Koch (cit. por Bassoe ") descreveram ninhos de células gliais atípicas em dois casos de neurofibromatose. Bielschowski (cit. por Bassoe "), assim como Penfield e Young ${ }^{13}$, relacionou as atipias celulares do córtex ccrebral de portadores da moléstia de Recklinghausen com alteraçōes encontradas na moléstia de Bourneville. Vários outros autores $\$, \&$ também defendem esta opinião. Van der Honve estudou as alterações oculares comuns às moléstias de Recklinghausen, Bourneville e Von Hippel-Lindau; admitindo que o ponto de maior contacto entre elas seria constituido pela existência de tumores cutâneos aos quais deu a denominaçāo de facomas, introduziu a designação de facomatoses pala essas moléstias. Para Van der Hoeve facomas são nódulos pigmentares cutâneos, sem células névicas, capazes de transformação maligna. Von Bogaert 22 , estudando o problema das relações entre essas doenças, procurou classificá-las, juntamente com a idiotia xerodérmica, a queratose palmoplantar heredofamiliar e a ictiose congênita associada à epilepsia, dentro de um quadro mórbido único por êle designado como displasia neuro-ectodérmica congênita. Essa designação é mantida pela escola francesa.

Numerosos estudos foram realizados sôbre a incidência familial da neurofibromatose, sendo que a primeira referência a êsse respeito data de 1818 (Schiffner, cit. por Borgerg ${ }^{3}$ ) muito antes da descrição da moléstia por von Rocklinghausen. Preiser e Davenport 15 em 1918, Zimmer em 1936 (cit. por Borberg ${ }^{3}$ ) e vários outros autores relataram séries de famílias portadoras da forma periférica da moléstia. Gardner e col.4, ' descreveram uma família com seis gerações afetadas pela forma central, citando várias outras referidas na literatura. São uniformes as verificaçōes de que a moléstia se transmite com caráter mendeliano dominante, da mesma maneira que as demais displasias neuro-ectodérmicas congênitas. Em sua incidência familial a mo- 
léstia pode apresentar-se seja sob a forma central, seja sob a forma periférica, seja com associação das duas. Formas incompletas com a presença de apenas um dos elementos, tais como lesões cutâneas, lesões oculares e neurinomas bilaterais de acústico, são freqüentes nas famílias estudadas. Ainda quanto à incidência familial deve ser assinalada a possível concomitância de formas de neurofibromatose com a moléstia de Bourneville e com a angiomatose encéfalo-trigeminada; Schull e Crowe 20 julgam, entretanto, tratar-se de associação, em uma mesma família, dos gens responsáveis por essas moléstias.

\section{OBSERVAÇŌES}

Caso 1 - A. R. M., 15 anos de idade, sexo feminino, branca, brasileira, internada pela primeira vez em 13-5-1947 (reg. H.C. 46954), com 8 anos de idade. Apresentava paraplegia crural, sensitivo-motora e espástica, desenvolvida em 6 meses; além dêsse quadro medular, o exame mostrava exoftalmo à direita com deslocamento do bulbo ocular para baixo, paresia do músculo reto interno direito, amaurose à direita com atrofia de papila óptica e abolição do reflexo fotomotor. A punçũo lombar mostrou bloqueio completo à manobra de Stookey e dissociação aibuminocitológica ( $150 \mathrm{mg}$ de proteínas por $100 \mathrm{ml}$ e 0 células). A perimielografia (ascendente e descendente) mostrou bloqueio entre $D_{4}$ e $D_{9}$ (fig. 1). Operada em 12-61947, foi retirado um tumor intrarraquidiano extradural (neurofibroma).

O quadro medular regrediu inteiramente; entretanto, com o correr dos anos, o exoftalmo à direita acentuou-se, ao mesmo tempo que todos os núsculos extrinsecos do globo ocular se paralisavam. Em meados de 1952, a paciente foi internada em outro hospital, tendo sido realizado o esvaziamento da órbita direita, com retirada parcial do tumor que, através do buraco óptico alargado, se propagava para o interior do crânio; o exame histológico mostrou tratar-se de meningeoma psamomatoso. Logo em seguida a paciente começou a notar diminuição da acuidade auditiva à direita e depois à esquerda, déficits ê jtes que se acentuaram progressivamentc. Гm 12-10-53 ela foi reinternada na Clinica Neurológica, tendo o exame neurológico revelado: hipoacusia bilateral mais intensa à direita, limitação cio movimento do globo ocular esquerdo para fora e área de anestesia no território do nervo supra-orbitário direito, sendo êste último distürbio de origem cirủrgica.

Os exámes subsidiários foram orientados em dois sentidos: a) para pesquisar a expansão intracraniana do meningeoma da cavidade orbitária direita; $b$ ) para investigar a existência de tumorações na lossa posterior. Exame radiológico do crânio: à esquerda, aumento do meato auditivo interno; à direita, alargamento do buraco óptico, esclerose granular fina do fundo da órbita com alargamento irregular da fenda esfenoidal, esclerose óssea do teto da órbita e erosão da extremidade interna da pequena asa do esfenóide, em relação com sombra retro-orbitária de densidadc cálcica. Iodoventriculografia: na ocasião foi considerada como normal. Angiografia via artéria carótilla direita: o segmento inicial da artéria cerebral anterior apresentava-se elevado e deslocado para trás, descrevendo, na incidência lateral, curva de concavidade anterior em correspondencia com a sombra cálcica acima referida. Eletrencefalografia: desorganização difusa predominando à direita, sem sinais seguros de localizaçāo.

Após a realização dêstes exames concluiu-se que: $a$ ) havia processo expansivo intracraniano, cuja natureza era provàvelmente idêntica à do tumor operado; $b$ ) não havia dados suficientes para se afirmar a existência de processos expansivos ao nivel de ambos os ângulos pontocerebelares. A paciente teve alta hospitalar temporária.

Reinternação em 28-12-1954, ocásião em que foi assinalado: paresia do músculo reto externo, exoftalmo, edema de papila (4 dioptrias), quadrantopsia temporal in- 


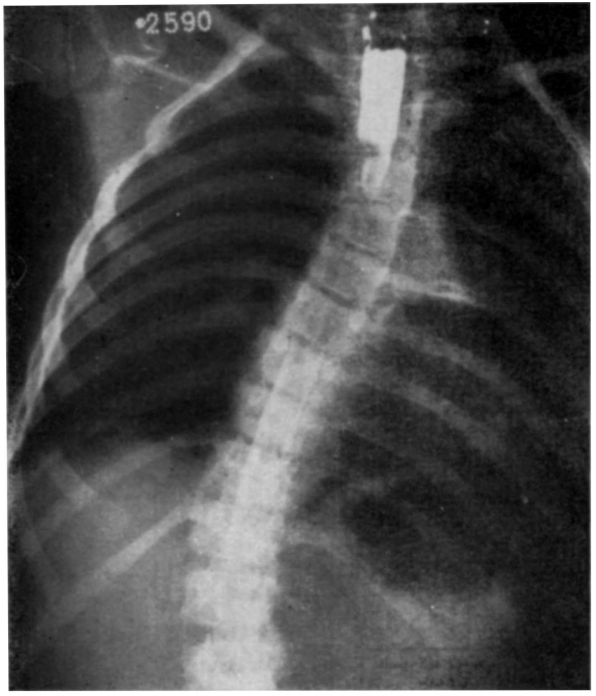

Fig. 1 - Caso 1 (A. R. M.). Escoliose dorsal. Perimielografia combinada (lipiodol ascendente $e$ descendente) mostrando bloqueio entre is corpos vertebrais de $D_{4}$ a $\nu_{y}$.

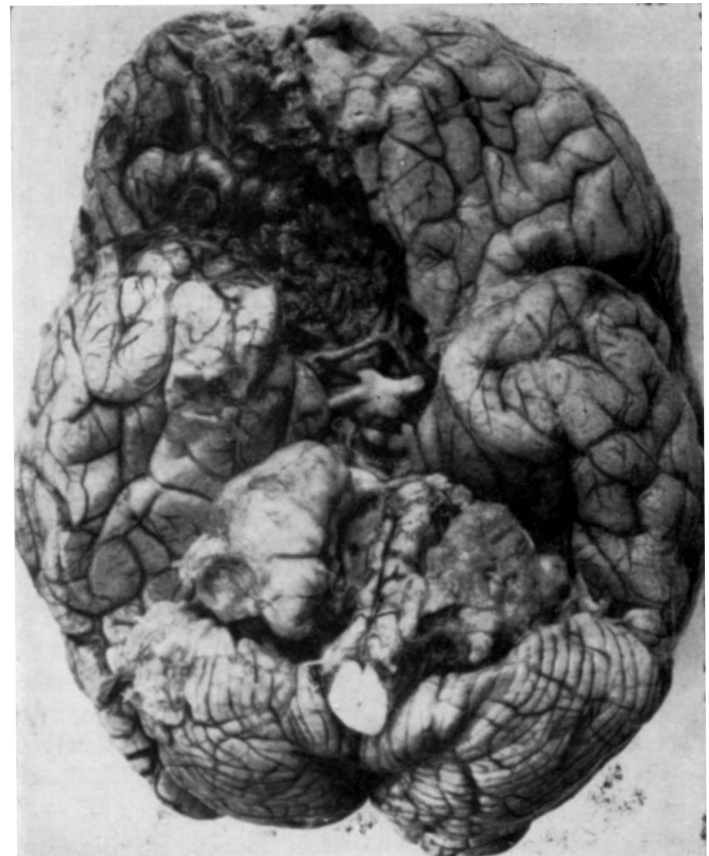

Fig. 2 -Cuso 1 (A. R. M.). Fotografia do encéfalo mostrando área cruenta na região frontal correspondente ao meningeoma da asa do esfenóide e os tumores dos ângulos pontocerebelares deformando a nonte, o bulbo e o cerebelo. 

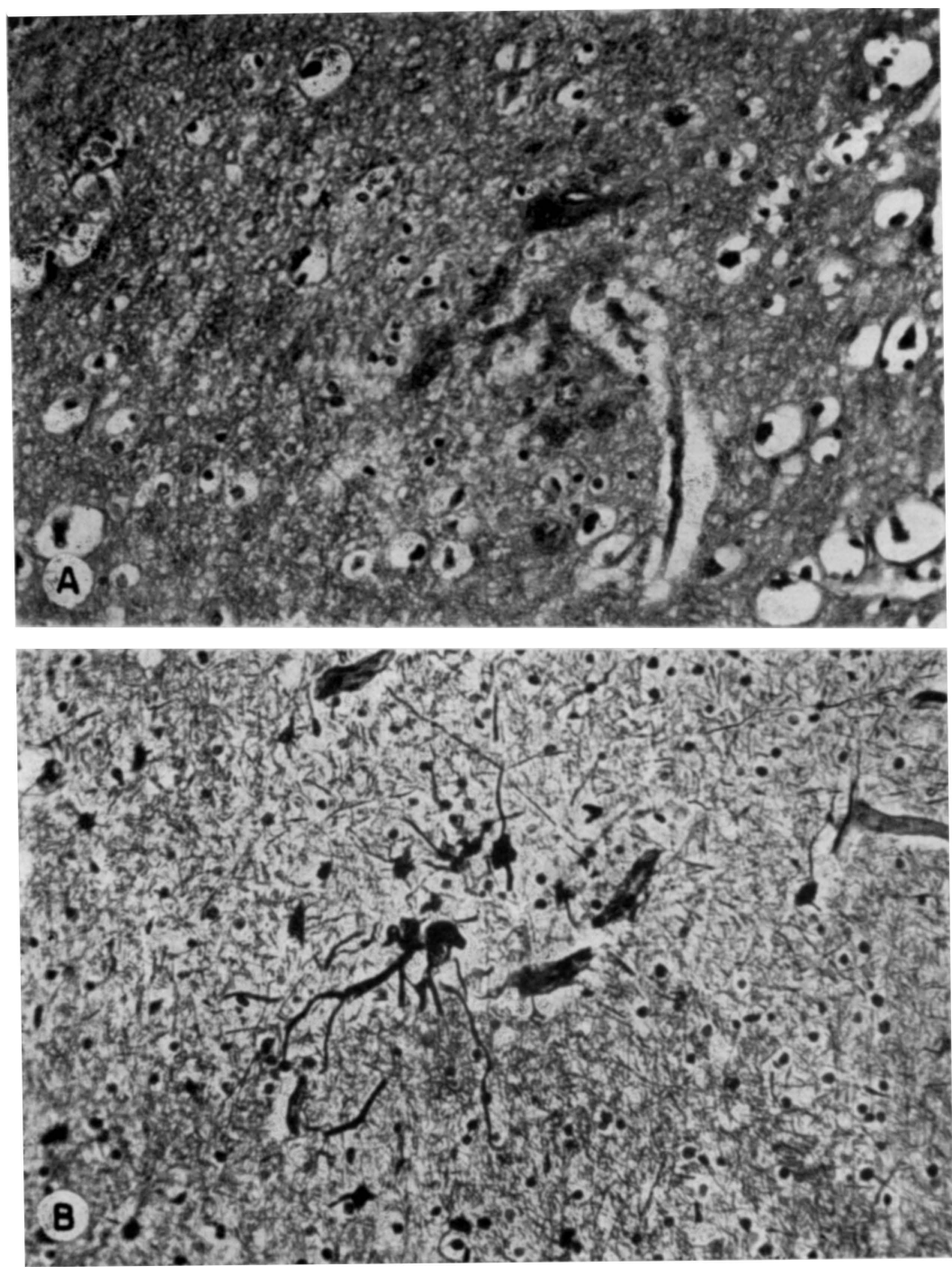

Fiq. 3 - Caso 1 (A. R. M.). Cortes histológicos do córtex cerebral, com os ninhos de células gliais atipicas. $E m A$, coloração pela inematoxilinaeosina; em $B$, tríplice impregnacio de Hortega $(30 x)$.

ferior com retração concêntrica do quadrante temporal superior, do lado esquerdo; acentuação da hipoacusia bilateral; arreflexia vestibular à prova calórica fria em ambos os lados; paralisia velo-faringea no lado direito. Carotidoangiografia à esquerda: sifão carotideo retificado e porção terminal da carótida interna empurrada para trás. Pneumencefalografia fracionada: inconclusiva. 
Foi realizada craniotomia frontal direita, sendo encontrada tumoração na região do quiasma e dos nervos ópticos (meningeoma da pequena asa do esfenóide). A extirpacão do tumor foi parcial devido a dificuldades decorrentes da própria localização. No pós-operatório a paciente não voltou mais à consciência, piorando progressivamente, vindo a falecer no $9^{\circ}$ dia.

Exame necroscópico (Dr. Dino de Almeida) - Autópsia 38704 - Descriçōo macroscópica: Ausência de globo ocùlar direito. Sinais de craniotomia frontotemporal direita. O exame do tegumento cutâneo e do tecido subcutâneo nada revelou. Broncopneumonia bilateral. Nódulo no nervo vago, no têrço distal do esôfago, do tamanho de um grão de feijão, de côr branca e consistência firme. Hemisfério cerebral direito de volume aumentado, apresentando, na face orbitária, aspecto cruento, com numerosos pontos hemorrágicos (fig. 2). A dura-mater correspondente apresenta alterações cirúrgicas e numerosos pequenos nódulos esbranquiçados. Nervo óptico direito atrofiado. Ponte e extremidade rostral do bulbo achatadas pela presença de dois nódulos neoplásicos, de tamanho comparável ao de uma noz, de consistência dura e superfície de corte com aspecto fibromatoso, localizados um em cada ângulo pontocerebelar (fig. 2). Os nervos acústicos são intimamente aderentes a êsses tumores. Os nervos trigêmio esquerdo oculomotor direito e glossofaringeu esquerdo mostram, em suas origens aparentes, nódulos semelhantes, porém de tamanho bastante menor. Discreta dilatação do sistema ventricular. Em quase tôdas as raizcs raquidianas, sobretudo nas da cauda equiina, existem nódulos fibromatosos. No fundo de saco dural, presença de gotículas de Lipiodol, bloqueadas por tecido fibroso. Na dura-mater correspondente aos segmentos inferiores da medula torácica, em sua face interna, existe um nódulo de consistência friável e de superfície finamente granulosa, que comprime a medula, deixando nela uma impressão crateriforme; êste nódulo é semelhante aos encontrados na dura-mater craniana.

Diagnósticos histológicos: Os tumores da dura-mater craniana e raquidiana são meningeomas fibroblásticos e psamomatosos. Os tumores radiculares e dos nervos cranianos são neurofibromas com predominância do tipo A de Antoni. Os tumores dos nervos periféricos são neurojibromas. No córtex cerebral: ninhos de células atipicas (fig. 3), constituidos por 10 a 20 células por corte, com núcleos irregulares, vesiculosos, bastante grandes (10 a 15 micra), às vêzes contendo nucléolo; os prolongamentos são irregulares e pouco numerosos; não foi demonstrada a presença da substância de Nissl nem de neurofibrilas; localização preferencial nas IV e V camadas e na substância branca subcortical; na substância branca a disposição preferencial é justavascular.

Caso 2 - A. S., 26 anos de idade, sexo masculino, branco, irasileiro, internado pela primeira vez em 7-4-1953 (reg. H.C. 317759) com 23 anos. Desde criança apresentava oftalmoplegia total à esquerda, com ptose palpebral, e hemiatrofia do hemicorpo direito. Seis meses antes da internação, começou a notar hipoacusia bilateral. Quatro meses depois sofreu queda, após a qual surgiram intensas dôres na coluna toracolombar, déficit motor nos membros inferiores e retenção urinária. Exame clinico-neurológico: paciente emagrecido, só se mantendo de pé com aumento da base de sustentação, fôrça muscular diminuida no hemicorpo direito, hipoestesia táctil nos pés, hipoalgesia na face lateral da côxa direita e paralisia dos $3^{\circ}$ e $4^{\circ}$ nervos cranianos à esquerda. Exame do liqüido cefalorraquidiano: punçāo lombar; provas de Stookey anormais, mostrando estar parcialmente bloqueado o canal raquidiano; dissociação albuminocitológica (140 $\mathrm{mg}$ de proteínas por $100 \mathrm{ml}$ e 0 células). Exame neuro-otológico: inexcitabilidade dos labirintos às provas calóricas e rotatórias, hipoacusia de percepcão à direita e hipoacusia discreta de condução à esquerda. Radiografias da coluna vertebral: fratura por esmagamento da metade anterior de $L_{1}$, moderada luxação posterior das vértebras a montante e diminuição do espaço intervertebral entre $D_{12}$ e $L_{1}$. Perimielografia: parada transitória do contraste ao nivel de $\mathrm{D}_{12}-\mathrm{L}_{1}$. Exame elétrico: sindrome elétrica de degenerescência parcial no território muscular do nervo cubital no punho; reasões elétricas anormais nos músculos gê- 
meos bilateralmente e no biceps crural à direita. Em 24-7-1953 o paciente foi operado, tendo side retirado extenso tumor da raiz $L_{1}$; o exame histológico mostrou tratar-se de neurofibroma. O paciente teve alta hospitalar, podendo andar e sem dôres, embora apresentasse discreta ataxia na marcha.

No inicio de 1955 , piorou a incoordenação dos membros inferiores, havendo, a mais, discreta cefaléia bitemporal. Em 5-7-1955 o paciente foi reinternado. Exame clínico-neurológico: pequenas mánchas côr de café com leite na côxa e no tórax, numerosos nódulos subcutâneos no dorso, sindrome cerebelar bilateral com predominância à direita, hipoestesia superficial em sela no território das últimas raízes sacras, paralisia dos $3^{\circ}$ e $4^{\circ}$ nervos cranianos à esquerda, nistagmo horizontal bilateral aos olhares laterais, hipoestesia no território do nervo trigêmeo bilateralmente com abolição dos reflexos corneanos; déficit motor nos músculos inervados pelo nervo trigêmeo esquerdo, surdez à direita, hipoacusia de percepçāo à esquerda, paresia do hemipalato esquerdo, da hemilaringe esquerda, papiledema bilateral. Eletrencefalografia: sinais de sofrimento cerebral nas áreas occipitais, predominando nitidamente à direita. Exame elétrico: sindrome elétrica de degeneração parcial no território do cíatico popliteu interno à direita e reaçôes elétricas anormais no músculo tibial anterior do mesmo lado. Biopsia de ródulo subcutáneo no dorso: neurofibroma. $R a-$ diografias do crânio: acentuado alargamento de ambos os poros acústicos. Iodoventriculografia: aqueduto cerebral e $4^{\circ}$ ventrículo deslocados para trás e para a esquerda, descrevendo, em incidência anteroposterior, larga curva de concavidade voltada para a direita; quadro de tumor do ângulo pontocerebelar direito (fig. 4).

Fig. \& - Caso 2 (A. S.). Iodoventriculografia: deslocamento do ventriculo rombencefálico para trás.

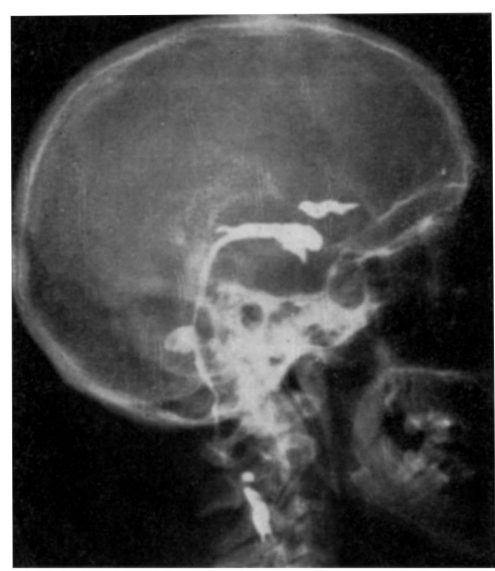

Em 17-8-1955 foi feita craniectomia de fossa posterior, lendo sido encontrado grande tumor no ângulo pontocerebelar direito, que foi extirpado parcialmente (neurofibroma). Hemorragia abundante e intenso trauma cirúrgico contra-indicaram a exploração do outro lado. O paciente apresentou-se em condições precárias no pósoperatório, vindo a falecer no segundo dia.

Exame necroscópico (Dr. M. R. Montenegro) - Autópsia 39674 - Descrição macroscópica: Incisāo de craniectomia de fossa posterior e cicatriz de laminectomia dorsal. Manchas côr de café com leite no tegumento cutâneo e nódulos no subcutāneo. Broncopneumonia confluente no pulmão direito. Dilutaçōes fusiformes, de consistência dura, nos troncos nervosos constituintes do plexo braquial direito. Nó- 
dulos esbranquiçados, de consistência fírme, aderentes ao bulbo olfatório direito e ao nervo óptico esquerdo. A dura-mater da convexidade apresenta duas formacões discóides firmemente aderidas, medindo $1,5 \mathrm{~cm}$ de diâmetro e $3 \mathrm{~mm}$ de altura (fig. 5). Espessamentos irregulares da foice cerebral na sua porção média. Encéfalo de volume aumentado; cone de compressão bulbar (fig. 5). Tumores de forma ovóide, nos ângulos pontocerebelares, de consistēncia dura e superficie de corte com aspecto fasciculado, medındo um dêles 2,5 e o outro $1,5 \mathrm{~cm}$ de diâmetro (fig. 5 ). Buracos auditivos internos alargados. Ponte, bulbo e hemisférios cerebelares com sinais de compressão. Sinais de intervencão cirúrgica recente ao nivel da face inferior do hemisfério cerebelar direito e do pólo caudal do tumor situado à direita. Pequeno tumor cortical localizado no córtex frontal, nāo adejente à dura-mater. Os tumores pontocerebelares que aparentemente se originam do nervo acústico, mostram, ao corte,

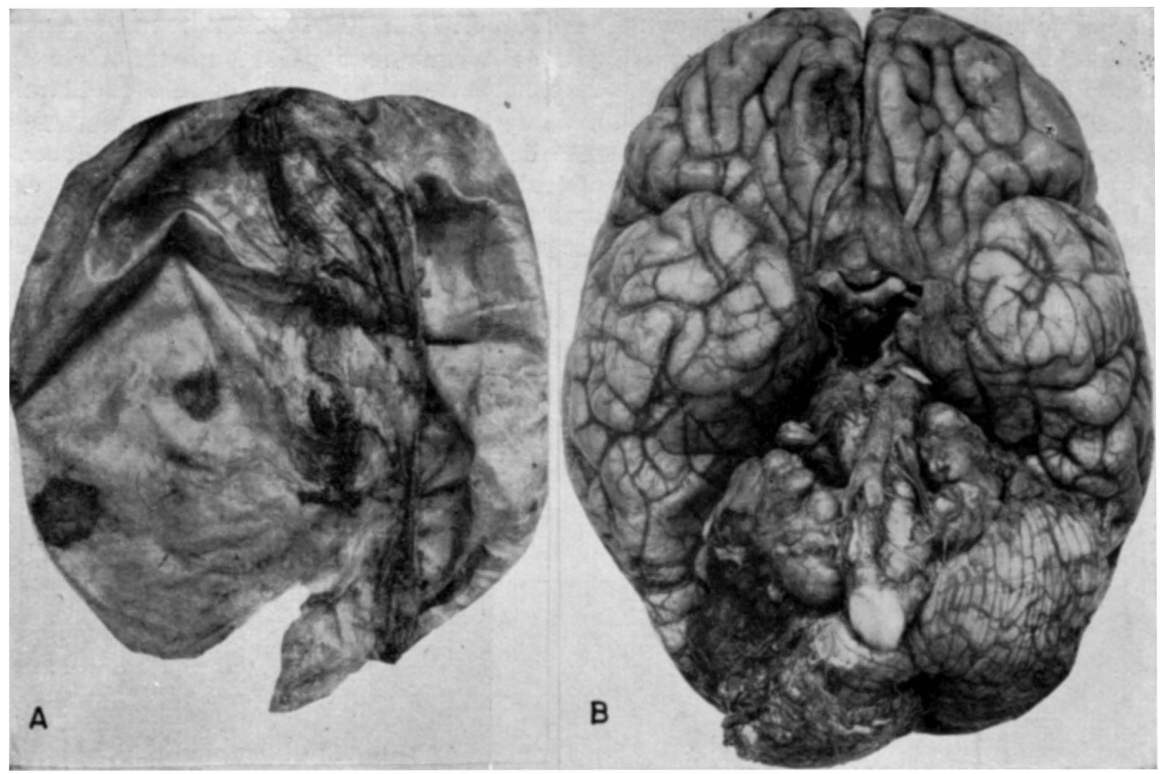

Fig. D - Caso z (A, D.). Em a, dura-mater da convexidade mostrando dois meningeomas discóides; em $B$, encéfalo com os tumores dos ângulos pontocerebclares, tendo sido o direito parcialmente retirado no ato cirurgico.

pequenos cistos contendo material viscoso. Lilatação ventricular. Na dura-mater espinal, em correspondêncıa com as regiões torácica alta e lombo-sacral, notam-se placas discóides semelhantes às descritas na dura-mater craniana. Ao nivel da cauda eqüina as raizes mostram-se aderidas entre si por tecido conjuntivo frouxo; estas raízes apresentam vários espessamentos ovóides, de consistência firme, coloração esbranquiçada e superfície de corte com aspecto fasciculado. Formações semelhantes, embora em menor número, foram encontradas nas regiões tolácica e lombar.

Diagnósticos histológicos: Os tumores radiculares são neurofibromas com áreas predominantes do tipo A. Os tumores da dura-mater são meningeomas psamomatosos, fibroblásticos e meningoteilais. Os tumores do plexo braquial assumem o aspecto da neurite intersticial hipertrófica (fig. 6). O nódulo cortical frontal é cons- 

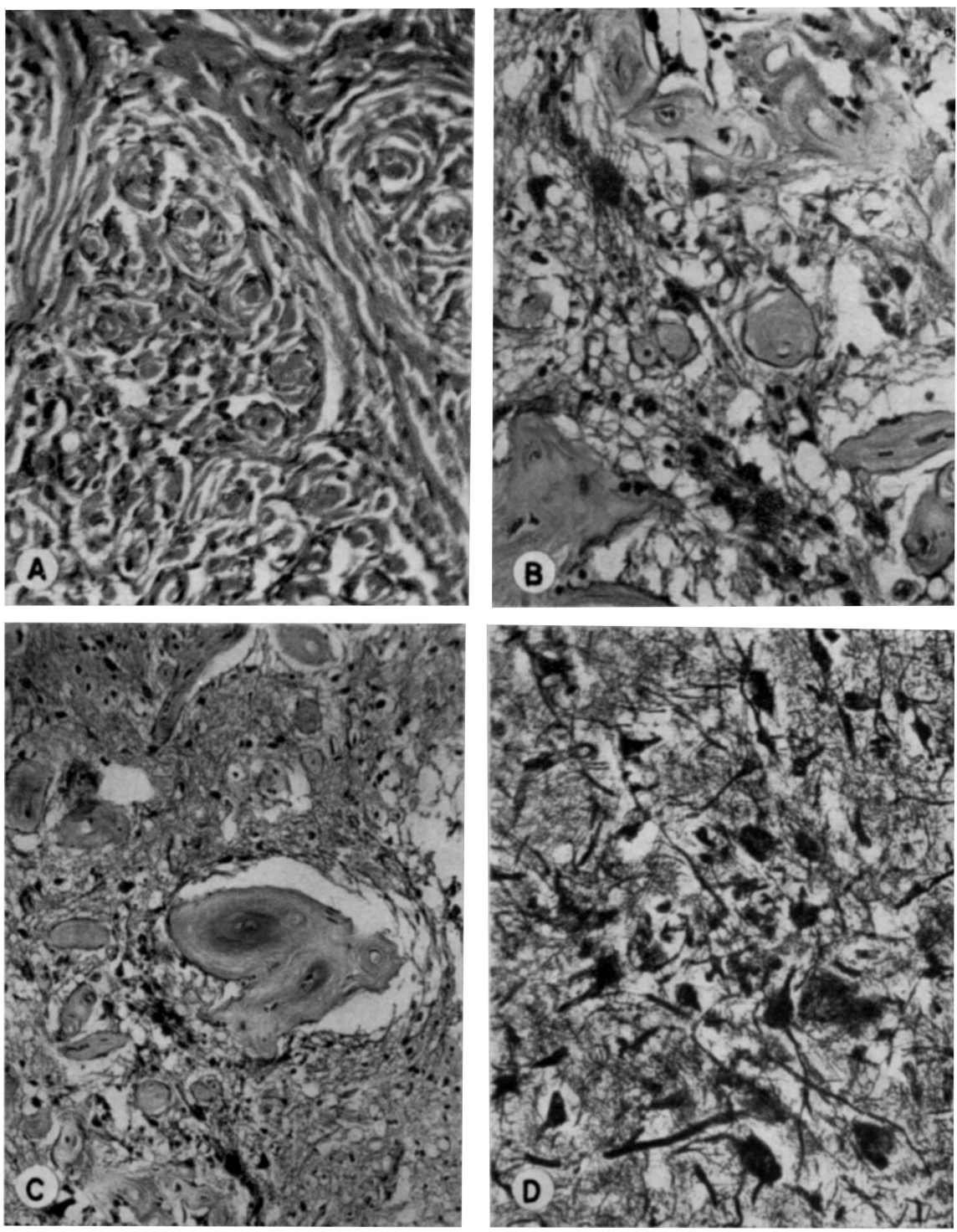

Fig. 6 - Caso 2 (A. S.). Em A, corte do tumor do plexo braquial mostrando feixes de fibras colágenas cortados transversalmente $e$ dispostos em tôrno dos axônios; quadro de neurite intersticial hipertrófica (H.E. $80 x)$. Em B, aspecto histológico do angioma cortical: hialinização dos elementos vasculares $e$ ninhos de células atipicas entre os vasos (H.E. $400 x)$. Em C, mesmo corte que em $B$, em menor aumento (H.E. $80 x$ ). Em D, córtex cercbral mostrando ninho de células atípicas (Hortega $400 x$ ). 
tituido por angioma com hiperplasia do tecido conjuntivo perivascular, com hialinização; atrofia do córtex interposto entre os vasos e presença de numerosos ninhos de células atipicas (fig. 6). Córtex cerebral: presença de numerosos ninhos de células atipicas (fig. 6).

CAso 3 - E. S. A., 31 anos, sexo feminino, parda, brasileira, internada em 18-11955 (reg. H.C. 394997). Onze meses antes da internação a paciente havia dado à luz, em parto normal, ao $5^{\circ}$ filho. Dois dias após êste parto, teve dôres abdominais violentas que duraram 3 dias, surgindo depois tremcres no membro superior direito e na cabeça, diminuição bilateral da audição, disartria e disfagia. Quatro meses mais tarde começou a ter desequilíbrio paı a andar, déficit êsse que se acentuou progressivamente, obrigando-a a permanecer acamada. Exame neurológico: astasia e abasia, ataxia cerebelar bilateral e tremores na cabeça. Não havia papiledema. Exame neuro-otolaringológico: hiporreflexia vestibular, nipoacusia do tipo misto, hiporreflexia do faringe. Radiografias do crânio: sela turca aumentada com desmineralização das clinóides posteriores. Exame do líqüido cefalorraquidiano: punção lombar; provas manométricas normais; hiperproteinorraquia (200 $\mathrm{mg}$ por $100 \mathrm{ml}$ ). Carotidoangiografia à direita normal. Iodoventriculografia: $4^{\circ}$ ventriculo discretamente deslocado para trás, sem desvios no plano médio sagital (fig. 7). Em 27-91955 foi feita pneumencefalografia fracionada que se mostrou insuficiente. No dia seguinte a paciente apresentou alterações respiratórias, vindo a falecer.

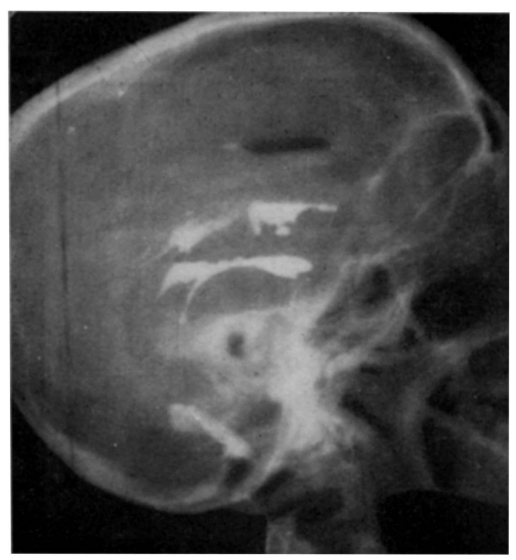

Fig. 7 - Caso 3 (E. S. A.). Iodoventriculografia: deslocamento do IV ventriculo para trás.

Exame necroscópico (Dr. A. Armbrust) - Autópsia 40058 - Descrição macroscópica: Edema cerebral e pequena hemorragia no espaço subaracnóideo da fossa interpeduncular. Nos ângulos pontocerebelares foram encontradas duas tumorações (fig. 8) de consistência firme, superficie externa nodular e superficie de corte fasciculada. Esses tumores comprimiam a ponte, recobriam os flóculos e a emergência dos nervos trigêmeos, faciais e acústicos. Sistema ventricular preenchido por coágulos sangüíneos. Bulbo e medula espinal sem alterações dignas de nota.

Diagnóstico histológico: Os tumores dos ângulos pontocerebelares são neurofibromas. Não foi feito exame histológico do encéfalo. 
Fig. 8 - Caso 3 (E. S. A.). Encéfalo mostrando os tumores dos ângulos pontocerebelares comprimindo o tronco e o cerebelo.

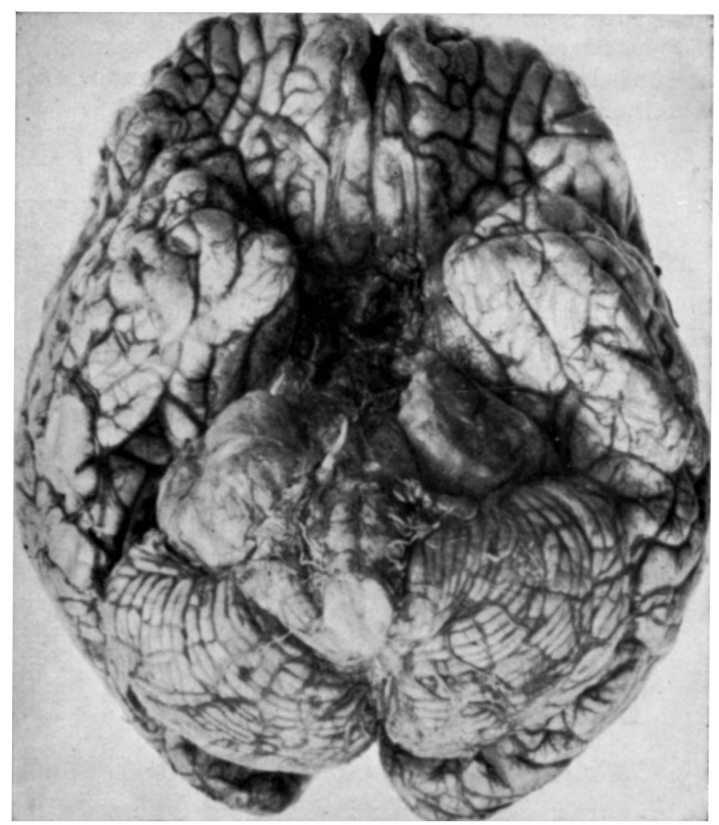

Caso 4 - Z. C. A., 17 anos, sexo feminino, branca, brasileira, internada em 126-1957 (reg. H.C. 478154). Cêrca de um ano antes da internação a paciente começou a sentir dormência e dôres no membro inferior direito. Quatro meses depois estas sensações atingiram também o membro inferior esquerdo e a paciente passou a apresentar cefaléia occipital e hipoacusia. Foi operada na Bahia por três vêzes: em agôsto de 1956 foi realizada apendicectomia e retirados nódulos do ovário (informaçoes fornecidas pela paciente); em outubro do mesmo ano foi feita biopsia de nódulo paravertebral; ulteriormente, foi feita laminectomı com retirada de três tumorações intra-raquidianas. Após a laminectomia desapareceram as aôres nos membros inferiores, permanecendo a dormência. A hipoacusia acentuou-se progressivamente, chegando pràticamente à surdez bilateral. Quinze dias antes da sua internação na Clínica Neurológica instalou-se disfagia.

Exame clínico-neurológico: nódulos no couro cabeludo; manchas côr de café com leite no abdome e no tórax; equilíbrio instável com tendência à queda para a direita; marcha com desvio para a direita; paresia dos músculos reto interno, obliquo inferior e elevador da pálpebra à direita; nistagmo horizontal bilateral de fixação e ao olhar extremo esquerdo; hipoestesja na hemiface direita, com anestesia de córnea; paresia facial tipo periférico à direita; hipoacusia de percepcão bilateral; inexcitabilidade vestibular à prova calórica. Exame elétrico: reaçâo de degeneração parcial em todo o território do nervo facial direito. Eletrencefalografia: moderada assimetria de amplitude do ritmo alfa nas áreas occipitais. Exame do liqüido cefalorraquidiano: punção suboccipital em decúbito lateral; pressão normal; hiperproteinorraquia (48 $\mathrm{mg}$ por $100 \mathrm{ml}$ ). Radiografias do crânio: alargamento dos orificios auditivos internos, calcificação dos plexos coróides dos ventrículos laterais, calcificação ao nivel da fossa posterior, hiperostose irontal direita. Pan-angiografia cerebral via carótida direita normal. Pneumencefaiografia fracionada: exame in- 
suficiente permitindo verificar, apenas, recalcamento do $4^{\circ}$ ventrículo para trás. Iodoventriculografia: quadro compativel com o diagnóstico de processo expansivo no ângulo pontocerebelar direito, não sendo excluida a possibilidade de processo semelhante à esquerda (fig. 9).
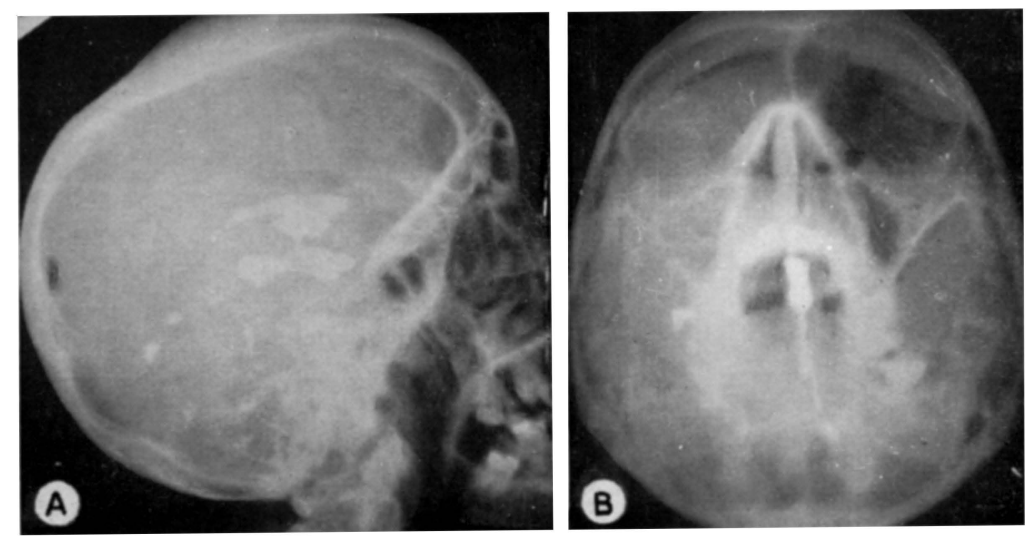

Fig. 9 - Caso 4 (Z. C. A.). Iodoventriculografia: deslocamento do $4^{\circ}$ ventrículo para trás ( $A$ ) e vara a esquerda ( $B)$.

Em 29-7-1957 foi feita craniectomia de fossa posterior, com retirada de um neurofibroma do ângulo pontocerebelar direito. Em 11-10-1957 a paciente foi reoperada para a extirpação de outro tumor idêntico à esquerda. A paciente teve alta apresentando como seqüelas: estrabismo, paralisia facial direita, paresia facial esquerda discreta, imobilidade da hemilaringe esquerda e surdez bilateral.

Diagnósticos histológicos: o nódulo subcutáneo paravertebral e os tumores intraraqueanos eram constituídos por neurofibromas (exames feitos na Bahia pelo Dr. $M$. Silvany Filho). O nódulo do subcutâneo e os tumores dos nervos acústicos eram neurofibromas, com predominância do tipo A nos processos intracranianos.

\section{COMENTARIOS}

Dos quatro casos, um não apresentava lesōes periféricas (caso 3, de forma central pura); nos demais estas lesões embora existissem eram bastante discretas ( $\operatorname{casos} 1,2$ e 4). Os ninhos de células gliais atípicas são elementos importantes para o diagnóstico da forma central, tendo sido encontrados nos dois casos ( 1 e 2) em que o córtex foi examinado histològicamente. Infelizmente a pesquisa não pôde ser feita no caso 3 , no qual só foram encontrados tumores dos nervos acústicos.

Tumores bilaterais de acústico têm sido encontrados freqüentemente em casos de neurofibromatose central. Gardner e col.4,5 estudaram exaustivamente uma familia na qual, em 6 geraçōes, a moléstia se caracterizava pela existência dêstes tumores. No entanto, Borberg ${ }^{3}$, em 25 casos de neurofibromatose central encontrou apenas um com tumores bilaterais de acústico. 
Outros autores apresentam percentagem variável 5, 10, 14, 18, 23. Nos quatro casos aqui relatados existiam tumores dêste tipo, constituindo manifestaçōes das mais importantes da doença ou, mesmo, a única (caso 3). Penfield 11, 12, 13 e, depois, Gardner e col.4, 5, chamaram a atenção para os tumores bilaterais do acústico, diferenciando-os dos solitários e considerando-os como manifestação da neurofibromatose, mesmo sem existência de outras lesões. Nos tumores solitários o aspecto histológico é o do fibroblastoma perineural (neurinoma) e nos tumores bilaterais as características são idênticas às dos tumores encontrados na neurofibromatose (neurofibromas).

Também é freqüente a existência de tumores intrarraquidianos, principalmente originados das bainhas radiculares $3,8,10,23$. Em 3 dos casos aqui relatados (casos 1, 2 e 4) a sintomatologia inicial foi devida à compressão radiculo-medular por tumores das raizes espinais. Este fato mostra a importância da pesquisa de outras lesões, principalmente tumores dos ângulos pontocerebelares, tanto em casos da forma periférica, como $\epsilon \mathrm{m}$ casos de neurofibroma intra-raquidiano. A procura de lesões centrais deve ser feita mesmo nos familiares de portadores de neurofibromatose central ou periférica. Em nosso material não foi verificada a incidència familial da moléstia, sendo de ressaltar, entretanto, que não foi feita pesquisa sistematizada nesse sentido.

Puech, Lereboullet e Bernard ${ }^{16}$ consideram importante para o diagnóstico diferencial entre neurofibromatose e esclerose tuberosa a inexistência, na primeira, de calcificações intracranianas. No caso 4 foram encontradas calcificações, não só dos plexos coróides dos ventrículos laterais, como também na fossa posterior. Entretanto, essas calcificações apresentavam aspecto diverso daquele que é encontrável na moléstia de Bourneville.

No caso 2, ao lado de lesões comumente encontradas na neurofibromatose (neurofibromas, meningeomas, ninhos de células atípicas), havia um angioma cortical e neurite intersticial hipertrófica no plexo braquial. Êstes processos são mais raros, tendo, entretanto, sido referidos em discussōes a respeito da patogenia da moléstia e das suas relações com entidades congêneres.

Para o diagnóstico das lesōes existentes em determinado caso são empregados os métodos rotineiros de investigação neurocirúrgica. Chamaremos, no entanto, a atenção para o diagnóstico dos tumores do nervo acústico. Em casos típicos os exames neurológico e otológico, associados ao estudo radiológico, permitem o diagnóstico; mas, em muitos casos, para o diagnóstico de certeza, torna-se necessário o uso de exames radiológicos contrastados. A iodoventriculografia, exame atualmente bastante usado para o diagnóstico de processos cirúrgicos localizados na fossa posterior, foi empregado nos 4 casos. No primeiro, o exame foi inicialmente considerado como normal, porém, ulteriormente foi possivel notar um deslocamento para trás do assoalho do $4^{\circ}$ ventrículo. Esste deslocamento foi demonstrado também nos demais casos. Em dois casos (1 e 3), não foram observados desvios laterais do $4^{\circ}$ ventrículo ou do aqueduto de Sylvius, enquanto que nos restantes 
(casos 2 e 4) havia desvio para a esquerda. A existência ou não de deslocamento no sentido lateral está condicionada principalmente ao volume das duas massas tumorais, indicando, no caso de haver desvio, qual o tumor mais volumoso. A pneumencefalografia fracionada, usada em dois casos, forneceu sinais imprecisos, tendo se mostrado mais perigosa que a iodoventriculografia; êste recurso diagnóstico deve, portanto, ser reservado para casos duvidosos e, assim mesmo, só para aquêles em que não haja hipertensão intracraniana. A angiografia via artéria vertebral não foi usada, tendo sido visibilizado o sistema vértebro-basilar no $4^{\circ}$ caso, por intermédio da pan-angiografia cerebral. Julgamos, no entanto, que a visibilização do sistema arterial vértebro-basilar (pela angiografia via artéria vertebral ou pela pan-angiografia) é de importância muito limitada nestes casos.

RESUMO

Os autores apresentam uma sistematização das lesões que podem ser encontradas na moléstia de Recklinghausen. Foram observados 4 casos de forma nervosa central da moléstia. Em todos existiam tumores bilaterais nos ângulos pontocerebelares, constituindo uma das manifestaçōes mais importantes da doença, sendo mesmo a única em um dos casos (forma central pura). Nos demais, portadores de formas mistas, além de outras lesões centrais (neurofibromas, meningeomas, ninhos de células atípicas), havia lesões periféricas discretas. Tumores intrarraquidianos originados nas bainhas radiculares foram os causadores da sintomatologia inicial em 3 pacientes. Em dois casos em que o córtex foi examinado histolòicamente, foram encontrados ninhos de células gliais atípicas, característicos da forma central da neurofibromatose. Duas lesões relativamente raras foram encontradas no segundo caso: angioma cortical e neurite intersticial hipertrófica do plexo braquial.

Em pacientes portadores de neurofibromatose periférica ou raquídea, como também em seus familiares, devem ser sempre procuradas lesões centrais, principalmente tumores do nervo acústico. O exame neuro-radiológico de escolha para confirmar o diagnóstico dêstes tumores é a iodoventriculografia.

\section{SUMMARY}

Central form of Von Reklinghausen nervous disease.

The authors present a systematization of the lesions seen in Recklinghausen's disease. Four cases of the nervous central type of the disease were studied. In all the cases there were bilateral pontine-cerebellar tumors, one of the most important findings for diagnostic purposes, which was the only manifestation of the disease in one of them (pure central form). In the others, with mixed types, besides various central lesions (neurofibromas, me- 
ningeomas) there were mild peripheral lesions. Intravertebral tumors orinating from radicular sheaths were the cause of the initial symptoms in three patients. In the two cases where the cerebral cortex was histologically studied, groups of atypical glia cells characteristic of the central type of neurofibromatosis were found. Two relatively rare lesions were found in the second case: cortical angioma and hypertrophic intersticial neuritis of the brachial plexus.

In patients with peripheral or intravertebral neurofibromatosis, as well as in their relatives, central lesions must be sought for, especially tumors of the acoustic nerve. The neurological diagnostic procedure of choice in such tumors is the contrasted ventriculography with Lipiodol.

\section{REFERÉNCIAS BIBLIOGRĀFICAS}

1. AJURIAGUerRa, J.; DAVID, M.; haguenEAU, F. - Gliose méningo-cérébelleuse et maladie de Recklinghausen. Rev. Neurol., 93:645-655 (outubro), 1955. 2. BASSOE, P.; NUZUM, F. - Report of a case of central and peripheral neurofibromatosis. J. Nerv. Ment. Dis., 42:785-796 (dezembro), 1915. 3. BORBERG, A. Clinical and genetic investigations into tuberous sclerosis and Recklinghausen's neurofibromatosis; contribution to elucidation of interrelationship and eugenics of the syndromes. Acta Psychiat. et Neurol. Scandinavica, suplemento 71, 1951. 4. GARDNER, W. J.; FRAZIER, C. H. - Bilateral acoustic neurofibromas. A clinical study and field survey of a family of five generations with bilateral deafness in thirtyeight members. Arch. Neurol. a. Psychiat., 23:266-302 (fevereiro), 1930. 5. GARDNER, W. J.; TURNER, O. - Bilateral acoustic neurofibromas. Further clinical and pathologic data on hereditary deafness and Recklinghausen's disease. Arch. Neurol. a. Psychiat., 44:76-99 (julho), 1940. 6. HEIN, G. E.; REAVIS, J. C. - Von Recklinghausen's disease; its relationship to other types of neuro-ectodermal dysplasia. Am. Practitioner, 1:29-35 (janeiro), 1950. 7. LICHTENSTEIN, B. W. - Neurofibromatosis (Von Recklinghausen's disease of the nervous system). Analysis of the total pathologic picture. Arch. Neurol. a. Psychiat., 62:822-829 (dezembro), 1949. 8. MAFFEI, W. E. - Tumores dos Nervos Periféricos. Tese de Docência Livre. Fac. de Med. da Univ. de São Paulo. Um volume com 87 páginas, São Paulo, 1939. 9. MASSON, P. - Tumeurs encapsuleees et bénignes des nerfs. Rev. Canad. Biol., 1: 209-343 (março), 1942. 10. PAGÈS, P.; LAFON, R.; GROS, C.; MINVIELLE, J. Formes centrales (cérébrale et médullaire) de la maladie de Recklinghausen. Rev, Neurol., 83:483-491 (novembro), 1950. 11. PENFIELD, W. - Cytology and Cellular Pathology of the Nervous System, vol. 3. Paul B. Hoeber Inc., Nova York, 1932, págs. 955-990. 12. PENFIELD, W. - The encapsulated tumors of the nervous system. Surg., Gynec. a. Obst., 45:178-188 (agôsto), 1927. 13. PENFIELD, W.; YOUNG, A. W. - The nature of von Recklinghausen's disease and the tumors associated with it. Arch. Neurol. a. Psychiat., 23:320-344 (fevereiro), 1930. 14. POURSINES, Y.; ALliEZ, J.; TATOSSIAN, A. - Forme centrale terminale de neurogliomatose de Recklinghausen. Tumeurs parenchymateuses multiples de l'encéphale avec localisation mésocéphalique dominante. Rev. Neurol., 92:607-611 (junho), 1955. 15. PREISER, S. A.; DAVENPORT, C. B. - Multiple neurofibromatosis (von Recklinghausen's disease) and its inheritance: with description of a (ase. Am. J. Med. Sc., 156:507540 (outubro) 1918. 16. PUECH, P.; LEREBOULLET, J.; BERNARD, P. - Sclérose tubéreuse et tumeurs cérébrales. Rev. Neurol., 77:225-246 (setembro-outubro), 1945. 17. RASMUSSEN, S. B. - An account of the microscopical examination in a case of centralized neurofibromatosis with a meningioma in the lateral ventricle. Acta Chir. Scandinavica, 85:203-212 (janeiro-marȩo), 1941. 18. RODRIGUEZ, B.; MÉDOC, J.; BERETERVIDE, K. V. - Contribution à l'étude des formes centrales de la maladie de Recklinghausen. Une entité particulière: la gliomatose multiple du névraxe. 
Rev. Neurol., 97:109-120 (agôsto), 1957. 19. SCHARENBERG, K.; JONES, E. Diffuse glioma of the brain in von Recklinghausen's disease. A study with silver carbonate. Neurology, 6:269-274 (abril), 1956. 20. SCHULL, J.; CROWE, F. W. Neurocutaneous syndromes in the M. kindred. A case of simultaneous occurrence of tuberous sclerosis and neurofibromatosis. Neurology, 3:904-909 (dezembro), 1953. 21. THANNHAUSER, S. J. - Neurofibromatosis (von Recklinghausen) and osteitis fibrosa cystica localizata e disseminata (von Recklinghausen). Medicine, 23:105-149 (maio), 1944. 22. VAN BOGAERT, L. - Les dysplasies neuro-ectodermiques congénitales. Rev. Neurol., 63:353-398 (março), 1935. 23. WERTHEIMER, P.; DECHAUME, J.; LECUIRE, J.; MOULIN, J. - Réflexions sur la coexistence de neurinomes multiples, de méningiomes et de gliomes encéphaliques dans la maladie nerveuse de Recklinghausen. A propos des Chitoneuromes. Neurochirurgie, 3:145-154 (abril-junho), 1957.

Clínica Neurológica. Hospitul das Clínicas da Fac. Med. da Univ. de Săo Paulo - Caixa Postal 3461, São Paulo, Brasil. 